\title{
High performance PV system based on artificial neural network MPPT with PI controller for direct current water pump applications
}

\author{
Hussain A. Attia \\ Department of Electrical, Electronics \& Communications Engineering, American University of Ras Al Khaimah, \\ United Arab Emirates
}

\begin{tabular}{l} 
Article Info \\
\hline Article history: \\
Received Dec 21, 2018 \\
Revised Feb 22, 2019 \\
Accepted Mar 23, 2019 \\
\hline Keywords: \\
ANN \\
DC-DC converter \\
MATLAB/Simulink \\
MPPT \\
PI controller \\
Power requirement \\
PV array \\
Standalone PV system
\end{tabular}

Article Info

PV system

\begin{abstract}
This paper presents a new design of a standalone photovoltaic system which is supplying the required power to a direct current water pump that have difficulty to supply by the utility electricity. The system is controlled by an artificial neural networks (ANN) algorithm with function softening by PI controller that to guarantee the maximum power point tracking (MPPT) working conditions. A parallel connected PV array is designed to supply the required power to the water pump. The proposed design considers Permanent Magnet DC motor (PMDC) of 48 Volts, and 500 Watts as a water pump's motor, the direct current (DC) pump is adopted to avoid the complexity of the alternating current $\mathrm{AC}$ pumping system which includes inverter, power filter, and insulated step up transformer, so the presented design avoids the mentioned AC system components. A feed forward ANN algorithm is adopted in this study to produce the reference voltage for the MPPT functioning of the PV system, Proportional Integral (PI) controller is inserted to soften the MPPT controller performance. System design, MATLAB simulation with results and the results' analysis all are presented in this paper. The study conclusion confirms the effectiveness of the proposal as a successful system for practical applications.
\end{abstract}

Copyright (C) 2019 Institute of Advanced Engineering and Science. All rights reserved.

\section{Corresponding Author:}

Hussain Attia,

Electrical, Electronics \& Communication Engineering Dept.,

American University of Ras Al Khaimah,

Ras Al Khaimah, 10021, UAE.

Email: 1sntl@ccu.edu.tw

\section{INTRODUCTION}

Due to the difficulty of reaching the grid electricity to the remote farms, the renewable energy sources are representing an ideal alternative to supply the required electrical power to the remote farms loads such as water pump. Solar energy is playing major role as an important renewable energy source due to its cleanness, zero cost and everywhere availability. Photovoltaic (PV) system function is producing the required electricity by converting the solar energy to direct current electrical power. The PV panel produced electricity is affected by the weather conditions, such as irradiation and temperature levels. These levels are fluctuate the instantaneous output power of the PV panel. The harvested power from the PV panel is affected positively by the irradiance while affected negatively by the ambient temperature [1-4]. The PV panel contents a matrix of basic solar unit which is a solar cell, these cells are connecting in series and/or in parallel based on the required specifications from the panel. In other words, to increase the level of panel's output voltage, the number of serially connected cells will be increased whereas to increase the level of panel's output current, the number of parallel connected cells will be increased.

Due to the non-linearity of the solar power response during the fluctuation in the weather 


\section{PROPOSED SYSTEM}

A standalone PV system is proposed in this study to deliver the electrical power to water pump of direct current motor type. Figure 1 shows the block diagram of the proposed system, the system is started by a parallel connected solar PV array which includes 3 panels of SPR-E20-327 module. For efficient harvesting of electrical power from solar energy to be used as DC link power, an artificial neural network (ANN) with proportional integral (PI) controller are designed to control the included buck-boost DC-DC converter that to guarantee working in maximum power point (MPP) conditions. The converter is responsible to deliver the required electrical power to the next block of a direct current load. The DC load is represented by battery charger, battery bank of $48 \mathrm{~V}$ and $100 \mathrm{~A} \cdot \mathrm{H}$ (four serially connected batteries of $12 \mathrm{~V}$ and $100 \mathrm{~A}$, and DC drive with DC motor. The role of battery bank is guaranteeing the pump working during the night hours. To control the speed of the water pump's DC motor of 48 Volts, and 500 Watts PMDC motor, a direct current speed drive is included in the proposed block diagram, the speed drive is responsible on controlling the pump speed by controller is included in the proposed system block diagram. The study in this paper focuses on the challenge of guaranteeing MPP work conditions by integrating the ANN algorithm with the PI controller. In addition, the required power calculation for remote water pump applications is presented.

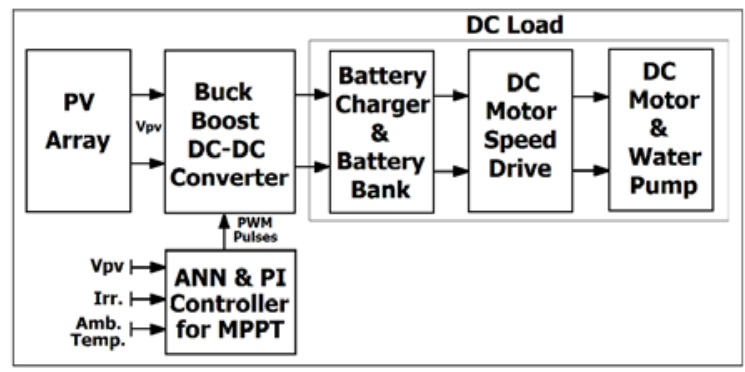

Figure 1. Block diagram of the proposed stand-alone PV system for water pump application

\subsection{PV array design}

The presented design of the PV array includes three parallel connected panels of module type SPR-E20-327, this module consist of 96 serially connected solar cells of efficiency $20.4 \%$, and Monocrystalline type. The specifications of the selected solar module are shown in Table 2.

Table 2. PV module spr-e20-327 specifications with array arrangement

\begin{tabular}{cc}
\hline Parameter & Value \\
\hline Rated Voltage (Vmpp) & $54.7 \mathrm{~V}$ \\
Rated Current (Impp) & $5.98 \mathrm{~A}$ \\
Open-Circuit Voltage (Voc) & $64.9 \mathrm{~V}$ \\
Short-Circuit Current (Isc) & $6.46 \mathrm{~A}$ \\
Avg. Panel Efficiency & $20.4 \%$ \\
Max. Power (Pmpp) & $327 \mathrm{~W}$ \\
Power Tolerance & $+5 /-0 \%$ \\
No. of Cells & 96 \\
Number of parallel lines $\left(N_{P}\right)$ & 3 \\
Number of series panels $\left(N_{S}\right) /$ line & 1 \\
Array power (Pmpp) $=3 \times 327 \mathrm{~W}$ & $981 \mathrm{~W}$ \\
\hline
\end{tabular}

The quantity of the produced power has nonlinear proportionality with the irradiation level and the ambient temperature. Irradiation level of incident light has positive proportionality whereas the ambient temperature has negative proportionality. Figure 2 shows the equivalent electric circuit of the solar cell, in which the output current of solar cell $I_{P V}$ represents the total generated current $I_{S C}$ minus the diode current $I_{D}$ and minus the shunt resistor $R_{P}$ current. The output current is passing through the serial resistor $R_{S}$. At series connection of the solar cells, the resultant voltage will increase to a level proportional to the number of series connected cells $N_{S}$, at the same connection, the total series resistance $R_{S-E Q}$ is also proportional with Ns. On the other side, in parallel connection of solar cells, the resultant level of output current will positively proportional to the number of parallel connected cells $N_{P}$, and the total parallel resistance $R_{P-E Q}$ is inversely proportional with $N_{P}$. (1) to (9) are showing the above explanation with respect to the equivalent 
circuit of the solar cell of Figure 2 [3-21]. The output PV array voltage equals to the voltage of one panel due to the parallel connection whereas the total current of the PV array equals to the summation of the 3 panels' currents as shown in Figure 3 and (6), and (7). As shown in Figure 3, the total output current at maximum power point (MPP) condition equals to $18 \mathrm{~A}$ approximately, whereas the level of the delivered power to the direct current load reaches to $1 \mathrm{~kW}$ approximately.

$$
\begin{aligned}
& I_{S C}=I_{D}+I_{P}+I_{P V} \\
& I_{P V}=I_{S C}-I_{D}-I_{P} \\
& I_{D}=I_{0}\left(e^{\frac{V_{D}}{V_{T}}}-1\right) \\
& I_{P}=\frac{V_{D}}{R_{P}} \\
& V_{P V}=V_{D}-R_{S} I_{P V} \\
& V_{P V_{-} A r r a y}=V_{P V} \\
& I_{P V_{-} A r r a y}=I_{P V} \times \text { No.of parallel lines } \\
& R_{P_{-} E Q}=\frac{N_{S}}{N_{P}} R_{P} \\
& R_{S_{-} E Q}=\frac{N_{S}}{N_{P}} R_{S}
\end{aligned}
$$

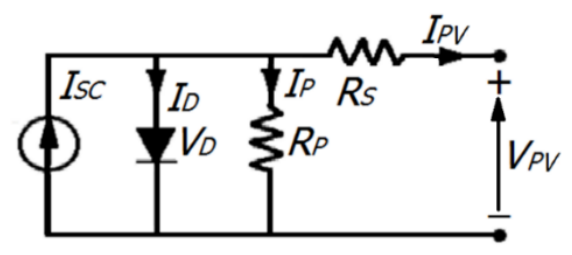

Figure 2. Equivalent circuit of solar cell

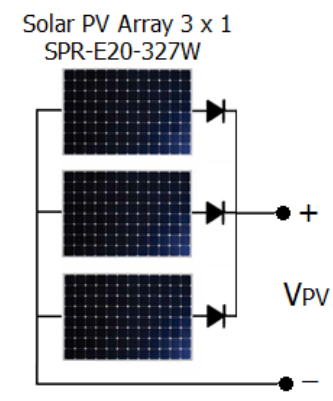

Figure 3. The solar PV array connection

The I-V curves of the solar array at 4 different levels of irradiance $\left(400 \mathrm{~W} / \mathrm{m}^{2}, 600 \mathrm{~W} / \mathrm{m}^{2}, 800\right.$ $\mathrm{W} / \mathrm{m}^{2}$, and $1000 \mathrm{~W} / \mathrm{m}^{2}$ ) with fixed ambient temperature of $25{ }^{\circ} \mathrm{C}$, and at 4 different levels of ambient temperature $\left(15{ }^{\circ} \mathrm{C}, 25{ }^{\circ} \mathrm{C}, 35^{\circ} \mathrm{C}\right.$ and $\left.45^{\circ} \mathrm{C}\right)$ with fixed irradiance level of $1000 \mathrm{~W} / \mathrm{m}^{2}$ all are shown in Figure 4. The nonlinearity behavior of the I-V curves are clearly monitored at different testing conditions. The P-V curves at same testing conditions are shown in Figure 5. From power curves, it is noticeable that the importance of working in MPP conditions for harvesting the maximum allowable levels of produced power. 


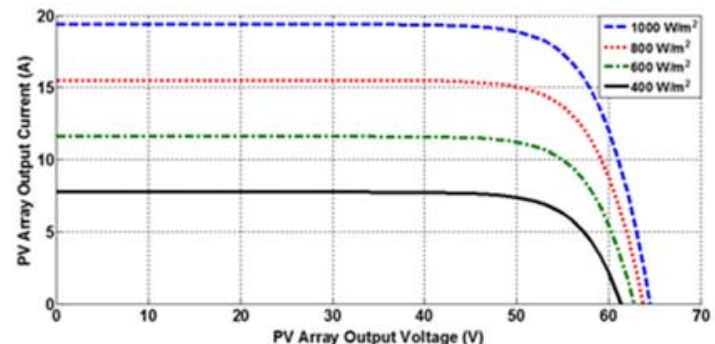

(a)

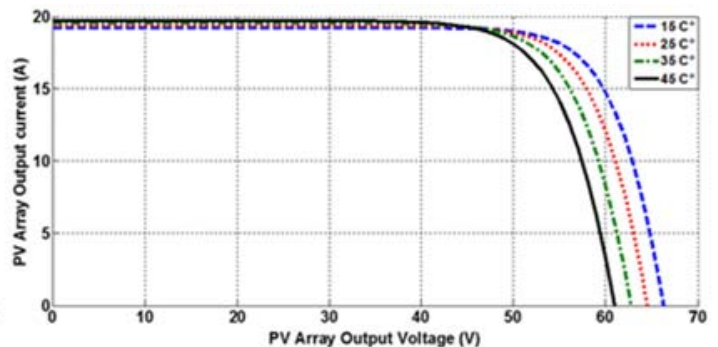

(b)

Figure 4. PV array of module (SPR-E20-327) characteristics; (a) I-V curves at fixed ambient temperature of $25^{\circ} \mathrm{C}$; (b) $\mathrm{I}-\mathrm{V}$ curves at fixed irradiance of $1000 \mathrm{~W} / \mathrm{m}^{2}$

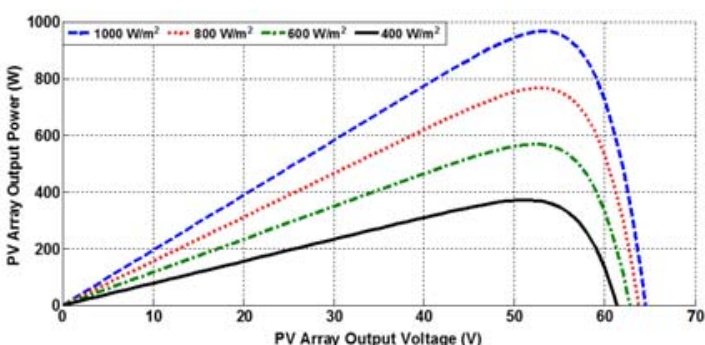

(a)

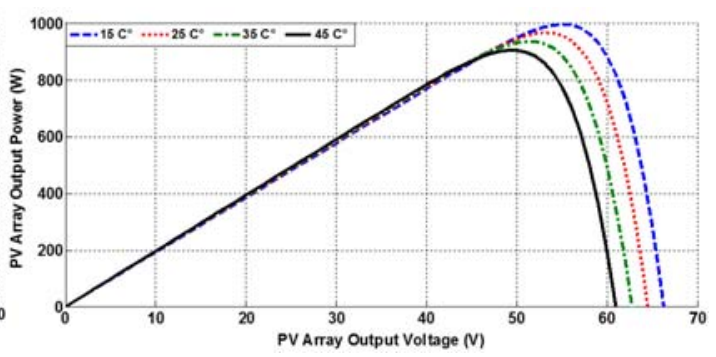

(b)

Figure 5. PV array of module (SPR-E20-327) characteristics; (a) P-V curves at fixed ambient temperature of $25^{\circ} \mathrm{C}$; (b) P-V curves at fixed irradiance of $1000 \mathrm{~W} / \mathrm{m}^{2}$

The design in this study considers $13.7 \mathrm{~V}$ to $14.7 \mathrm{~V}$ voltage range [25] as an allowable voltage for charging the $12 \mathrm{~V}$ battery. In other words, by adopting $13.7 \mathrm{~V}$ as the required voltage for normal charging, this is leading to the need of 55 Volts for charging function to the battery bank of $48 \mathrm{~V}$ with normal charging current of $10 \%$ of the battery $\mathrm{AH}$.

\subsection{Buck-boost DC-DC converter design}

The function of the converter is controlling the output voltage $V_{o}$ of the converter [13-15], [21-24] by bucking the input voltage $V_{i n}$ when the duty cycle $D$ width of the deriving pulse width modulation PWM pulses in a range less than 0.5 , whereas boosting $V_{\text {in }}$ when the duty cycle $D$ width in a range more than 0.5 as shown in (10). Here, it is deserve to mention that PWM is a common technique in literature. [2-24].

$$
V_{o}=-V_{\text {in }}\left(\frac{D}{1-D}\right)
$$

When the converter working in continuous conduction mode (CCM), the minimum value of the converter's inductor can be determined for a certain load $R$ at a certain switching frequency $f_{S}$ using (11).

$$
L_{\min }=\frac{R(1-D)^{2}}{2 f_{S}}
$$

The circuit of the converter includes capacitor of the minimum value limited by (12), where $V_{O}$ is the converter output voltage, and $\Delta V_{O}$ is the ripple of $V_{O}$.

$$
C=\frac{D}{R f_{S}} \frac{V_{o}}{\Delta V_{o}}
$$

\subsection{Artificial neural network (ANN) design}

Artificial Neural Network (ANN) represents a one of the common machine learning techniques which is able to solve problems of different types and levels of complexity. ANN is characterized by fast action in learning and response process with ability of producing accurate results regardless the system 
function [18-21]. To have accurate ANN performance, big data size of the input and output system's variables are required to be used for training or learning process that to have good trained relation between the input and the output variables to/from ANN respectively.

Currently neural networks are used as an efficient technique for maximum power point tracking MPPT objective by determining the reference voltages at any weather condition of different irradiance and ambient temperature. The reference voltage of the ANN is used to be tracked by the system converter that to guarantee the MPPT.

Normally the structure of the neural network ANN includes many layers starting by input layer, and ending by output layer, whereas in between these 2 layers, there is/are one/more than one hidden layer/s. The input data are received by input layer, Here it is deserve to mention that it is preferable the range of input data between minimum (0) and maximum (1), these data will be processed in the intermediate steps by the hidden layer/s, then the result of ANN processing will be delivered at the output layer of the ANN to be used as reference value in the controller. Figure 6 shows the structure of the fundamental unit in neural network which is the neuron.

The (13) shows a linear combination for all of the input variables $\left(X_{n 1}, X_{n 2}, X_{n 3}, X_{n 4} \ldots, X_{n N}\right)$ in the neuron to produce $Z$, which will be processed later by the activation function before delivering as final result $y_{n}$ of neuron's processing [26].

$$
Z=\sum_{i=1}^{N} W_{n i} X_{n i}+B
$$

There are 3 types of activation functions that can select one of them to do the desired process on the input $Z$ to the function. The (14)-(16) show the sigmoidal, the hyperbolic and the linear transfer functions respectively [21].

$$
\begin{aligned}
& y_{n}=f(z) \\
& f(z)=\frac{1}{1+\exp ^{-z}} \\
& f(z)=\frac{1+e^{-2 z}}{1-e^{-2 z}}
\end{aligned}
$$

There are 2 types of ANN, feed forward ANN, and feedback ANN. Feed-forward type allows travelling the signal from in to out, i.e. forward direction only without feedback, whereas the second type takes feedback information for adjusting the weights to reduce the error level [21, 26]. The adopted ANN type to do the MPPT function in this study is feed forward ANN.

Back propagation process is selected for learning process and updating the weights in the neural network algorithm. The mean square error (MSE) represents an important parameter to evaluate the accuracy of the designed ANN. MSE indicates the difference between the estimated value of the ANN and the target value as shown in (17) [26]. Low MSE means accurate ANN performance and vice versa.

$$
M S E=\frac{1}{Q} \sum_{k=1}^{Q} e(k)^{2}=\frac{1}{Q} \sum_{k=1}^{Q}(t(k)-a(k))^{2}
$$

Where $\mathrm{Q}$ is the elements number of the input vector, $\mathrm{e}(\mathrm{k})$ is the error, $\mathrm{t}(\mathrm{k})$ is the target, whereas $\mathrm{a}(\mathrm{k})$ is the ANN estimated output vector.

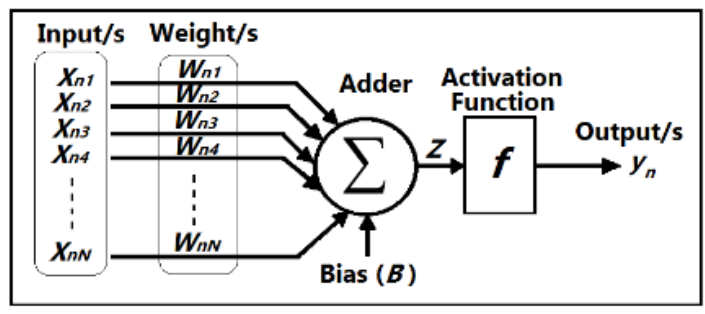

Figure 6. Neuron structure 
Figure 7, shows the detailed diagram of the proposed MPP tracker based on ANN algorithm and PI controller. As shown in Figure 7, the main function of the ANN is producing the estimated reference voltage which represents the PV array voltage at MPP, this voltage will be in different levels based on the weather conditions of irradiance and ambient temperature. The weather conditions will be monitored by these two input variables of ANN which receives the input variables by the 2 neuron input layer. The next layer is represented by the hidden layer of 20 neurons, all of these neurons receive the outputs of the input layer and doing the intelligent process to estimate the reference voltage, and this voltage will be delivered through the outside of the output layer. To work at MPP, the PV system must track the reference voltage, so the actual output voltage of PV array is measured to determine the difference with respect to the reference that to track the reference voltage based on the level of error signal by controlling the duty cycle of the pulse width modulated pulses. The pulses are driving the buck boost DC-DC converter to control the DC load voltage that to guarantee the maximum load power. The proportional integral PI controller is inserted after the ANN to soften the tracking function to the next reference levels and avoiding the sudden change in the error voltage $\operatorname{Err}_{V}$.

ANN needs to train or learn by using big size data as possible, in this study, the input variables are irradiance levels $(G)$ and ambient temperature $(T)$, whereas the output variable is the reference voltage at MPP condition for the PV array, and the range of trained data of the irradiance is from $25 \mathrm{~W} / \mathrm{m}^{2}$ minimum to $1000 \mathrm{~W} / \mathrm{m}^{2}$ maximum, whereas the range of trained data of the ambient temperature is from $5{ }^{\circ} \mathrm{C}$ minimum to $45{ }^{\circ} \mathrm{C}$ maximum. Here it is deserve to mention that, the arrays of input variables and the output variable are normalized before the training process that to have higher accuracy of ANN performance.

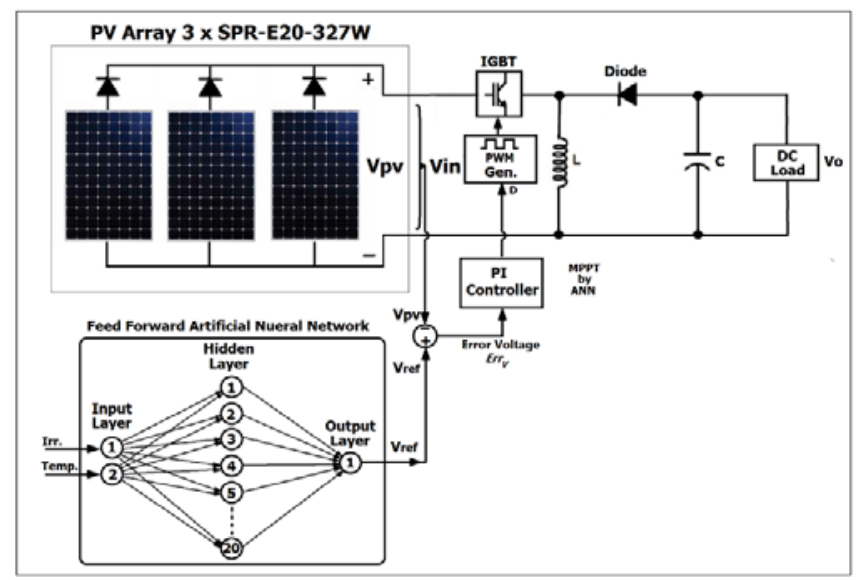

Figure 7. The proposed standalone PV system for MPPT function based on ANN algorithm

\section{PROPOSED SYSTEM}

The proposed PV system is simulated, tested and effectiveness evaluated via Simulink of MATLAB software. The system performance based on the designed neural network is evaluated with and without IP control, in addition, the system is evaluated without any controlling algorithm that to show the positive effect of the ANN role on the PV system effectiveness. Table 3 shows the designed parameters for the converter components and PI controller. The details of the simulated neural network are shown in diagram of Figure 8. As shown in Figure 8 (a), the designed ANN includes 2 input variables, hidden layer of 20 neurons, and output layer of 1 output variable. The ANN performance in terms of Mean Squared Error MSE is shown in Figure 8 (b). It is clearly noticeable the acceptable value of MSE at epoch 10 as shown in Figure 8 (b) that is equal to 7.4747e-5. Figure 9 shows the simulation results of load power levels for four equally intervals in a $2 \mathrm{sec}$ period. The DC load's power is measured with and without using the proposed MPP tracker of ANN and PI controller to show the performance effectiveness of the proposed solution. The results at fixed ambient temperature of $25^{\circ} \mathrm{C}$ and irradiances of $\left(600 \mathrm{~W} / \mathrm{m}^{2}, 750 \mathrm{~W} / \mathrm{m}^{2}, 900 \mathrm{~W} / \mathrm{m}^{2}\right.$, and $\left.450 \mathrm{~W} / \mathrm{m}^{2}\right)$ indicate the high effectiveness of the proposal in this study. 
Table 3. Proposed system parameters

\begin{tabular}{cc}
\hline Component/Parameter & Value \\
\hline DC Link Capacitor & $2.2 \mathrm{mF}$ \\
Converter Capacitor $C$ & $2.2 \mathrm{mF}$ \\
Converter Inductor $L$ & $2 \mathrm{mH}$ \\
Switching Frequency $f s$ & $30 \mathrm{kHz}$ \\
Load Resistor $R$ & $3.1 \Omega$ \\
Duty Cycle $D$ (without Control) & 0.5 \\
PI Parameters $P, I$ & $0.011,0.005$ \\
\hline
\end{tabular}

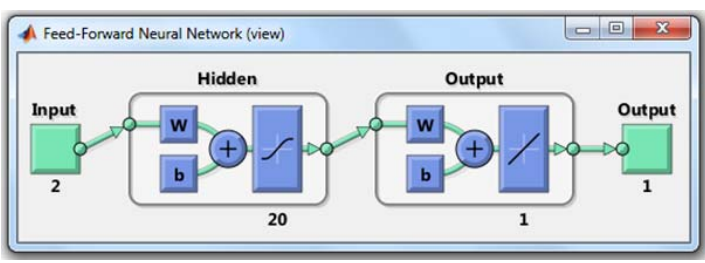

(a)

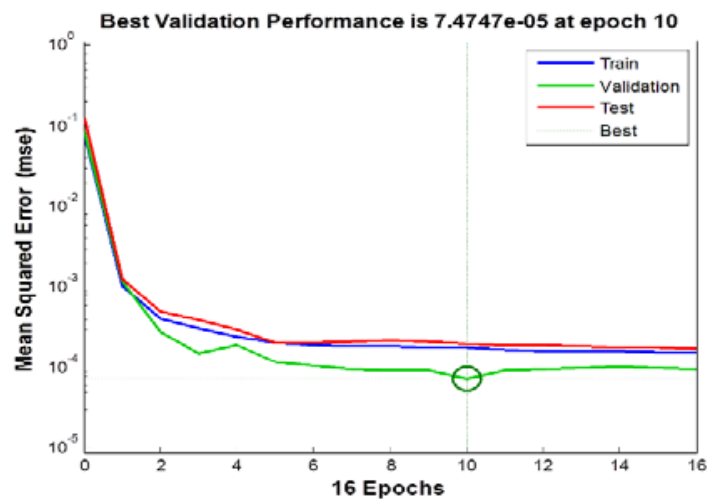

(b)

Figure 8. The designed artificial neural network ANN, (a) Feed-forward neural network structure,

(b) MSE performance

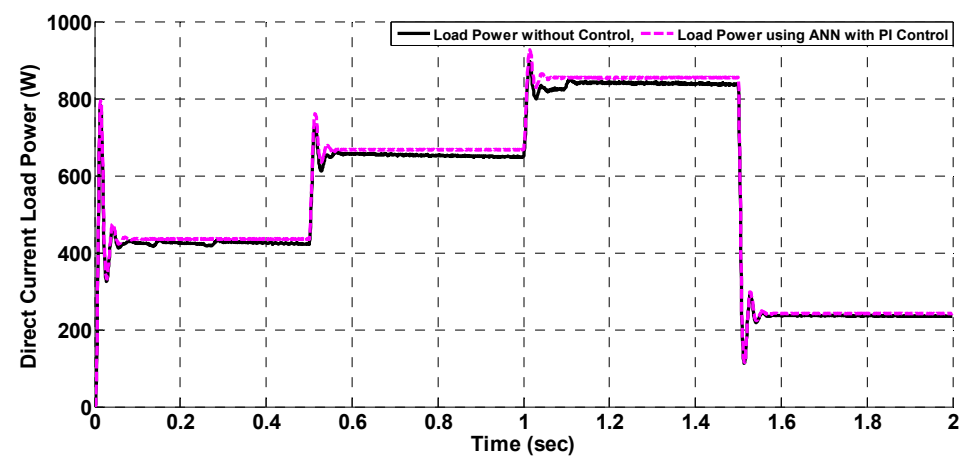

Figure 9. Simulation results of load power with and without the proposed ANN \& PI controller for MPPT function

\section{CONCLUSION}

A new design and simulation results of a certain MPP tracker based on the neural network algorithm with the PI controller is proposed in this study. The proposal focused on the challenge of delivering the required electrical power to the water pump's DC motor in remote farms. A full design of a $1 \mathrm{~kW}$ power PV system is considered to deliver half of this power for pump's motor running during day hours, whereas the second half of the generated power is designed to use for battery charging. A three parallel connected PV panels are adopted to produce the required DC electricity. To have maximum power point working conditions, a new design of artificial neural network ANN is proposed to produce the accurate reference voltage to be tracked by the designed buck-boost DC-DC converter before delivering to the DC load. The proposed direct current solution avoided the needs of alternating devices such as inverter, high order filter and step up transformer, this is leading to reduce system complexity and cost. In addition, indicates the successful system for practical applications.

Int J Pow Elec \& Dri Syst, Vol. 10, No. 3, Sep 2019 : 1329 - 1338 


\section{ACKNOWLEDGEMENTS}

The authors appreciate the financial support provided by school of engineering, American University of Ras Al Khaimah - UAE, www.aurak.ac.ae/en/school-of-engineering/.

\section{REFERENCES}

[1] YI Al-Mashhadany, HA Attia, "Novel Design and Implementation of Portable Charger through Low-Power PV Energy System," Advanced Materials Research, vol. 925, pp. 495-499, Apr 2014.

[2] H. A. Attia, T. K. S. Freddy, H. S. Che, W. P. Hew, A. El Khateb, "Confined Band Variable Switching Frequency Pulse Width Modulation (CB-VSF PWM) for Single-Phase Inverter with LCL Filter," IEEE Transaction on Power Electronics, vol. 32(11), pp. 8593-8605, Nov 2017.

[3] Hussain A. Attia, Beza N. Getu, Yousif I. Al-Mashhadany, "Design and Simulation of Dual Axis Solar Tracker for Optimum Solar Energy Absorption," The International Conference on Electrical and Electronics Engineering, Clean Energy and Green Computing (EEECEGC2013) EEECEGC2013, Dubai, UAE, Dec 2013.

[4] Y. I. Al-Mashhadany, Hussain A. Attia, "High Performance for Real Portable Charger through Low-Power PV System," International Journal of Sustainable and Green Energy, vol. 4(3-1), pp. 14-18, 2015.

[5] Attia H.A., Getu B.N., "Design \& Simulation of a Solar Tracking System for Optimum Energy Absorption," International Journal of Thermal \& Environmental Engineering, vol. 8(1), pp. 17-24, 2014.

[6] Hussain A. Attia, Y. I. Al-Mashhadany, Beza N. Getu, "Design and Simulation of a High Performance Standalone Photovoltaic System," ICREGA'14 - Renewable Energy: Generation and Applications, Springer Proceedings in Energy 2014, Jul 2014.

[7] Abdelaziz Y., Abdallah M., Rafik S., Houari S., "Optimization of partially shaded PV array using a modified P\&O MPPT algorithm," Leonardo Electronic Journal of Practices and Technologies, vol. 15(28), pp. 179-196, 2016.

[8] Lekshmy Rajan, R. Pradeep, "Performance Analysis of Maximum Power Point Tracking based Photovoltaic Module with Cuk Converter for Electrical Applications," International Journal of Innovative Research in Electrical, Electronics, Instrumentation and Control Engineering, vol. 1(1), pp. 20-25, 2013.

[9] Abdelwahed Touati, Elhassane Abdelmounim, Mohamed Aboulfatah, Ahmed Moutabir, Radouane Majdoul, "Improved Strategy of an MPPT Based on the Torque Estimator for Variable Speed Turbines," International Review on Modelling and Simulations (IREMOS), vol 8(6), pp. 620-631, 2015.

[10] Toshihiko Noguchi, Shigenori Togashi, Ryo Nakamoto, "Short-current pulse-based maximum-power-point tracking method for multiple photovoltaic-and-converter module system," IEEE Transactions on Industrial Electronics, vol. 49(1), pp. 217-22, 2002.

[11] Marouane El Azzaoui, Hassane Mahmoudi, Karima Boudaraia, "Sensorless Fuzzy MPPT Technique of Solar PV and DFIG Based Wind Hybrid System," International Review on Modelling and Simulations (IREMOS), vol. 10(3), pp. 152-159, 2017.

[12] B. N. Alajmi, K. H. Ahmed, S. J. Finney, and B. W. Williams, "Fuzzy-Logic-Control Approach of a Modified HillClimbing Method for Maximum Power Point in Microgrid Standalone Photovoltaic System," IEEE Transaction on Power Electronics, vol. 26(4), pp. 1022-1030, Apr 2011.

[13] Hussain A. Attia, "Comparative design of fuzzy logic controller for photovoltaic panel maximum power point tracking," International Conference on Electrical and Computing Technologies and Applications (ICECTA), Ras Al Khaimah, United Arab Emirates, Nov 2017.

[14] Hussain Attia, "Fuzzy Logic Controller Effectiveness Evaluation through Comparative Memberships for Photovoltaic Maximum Power Point Tracking Function," International Journal of Power Electronics and Drive Systems (IJPEDS), vol. 9(3), pp. 1147-1156, Sep 2018.

[15] A. H. El Khateb, N. Abd Rahima, J. Selvaraja, "Fuzzy logic control approach of a maximum power point employing SEPIC converter for standalone photovoltaic system," The 3rd International Conference on Sustainable Future for Human Security, SUSTAIN 2012, 3-5, Kyoto University, JAPAN, Nov 2012.

[16] Imam Abadi, Ali Musyafa, Adi Soeprijanto, "Design and Implementation of Active Two Axes Solar Tracking System Using Particle Swarm Optimization Based Fuzzy Logic Controller," International Review on Modelling and Simulations (IREMOS), vol. 8(6), pp. 640-652, 2015.

[17] Brindha Bala Krishnan, V. Ganapathy, S. Apna Priya, C. Naveen Kumar, "Design and Implementation of FPGA Based Fuzzy Controller for VIENNA Rectifier," International Review on Modelling and Simulations (IREMOS), vol. 7(3), pp. 387-393, 2014.

[18] Mathur D., "Maximum Power Point Tracking with Artificial Neural Network," International Journal of Emerging Science and Engineering (IJESE), vol. 2(3), Jan 2014.

[19] N. Kalaiarasi, S. Paramasivam, Sanchari Kundu, "Control of Z-Source Inverter Based PV System with MPPT Using ANFIS," International Review on Modelling and Simulations (IREMOS), vol. 7(5), pp. 797-806, 2014.

[20] R. Haque, "Transmission loss allocation using artificial neural networks," Master Thesis, University of Saskatchewan Saskatoon, Saskatoon, Canada, 2006

[21] Fathi A. O. Aashoor, "Maximum power point tracking techniques for photovoltaic water pumping system," Ph.D. dissertation, Dept. Elect. Elect. Eng., Univ. of Bath, Claverton Down, UK, 2015.

[22] Hussain A Attia, Amjad Omar, Maen Takruri, "Design of decentralized street LED light dimming system," 5th International Conference on Electronic Devices, Systems and Applications (ICEDSA), Ras Al Khaimah, United Arab Emirates, Dec 2016. 
[23] Hussain Attia, Amjad Omar, Maen Takruri, Halah Y. Ali, "Pulse Width Modulation Based Decentralized Street LED Light," International Journal of Power Electronics and Drive System (IJPEDS), vol. 8(3), pp. 1238-1247, Sep 2017.

[24] M. H. Rashid, "Power Electronics - Circuits, Devices, and Applications," 3rd Edition Pearson Education: Academic Pr, 2004.

[25] Vijay Sharma, "Batteries, Chargers \& Alternators Excerpt from Inverter Charger Series Manual," SAMLEX AMERICA, [Online], Available : www.samlexamerica.com

[26] Hudson Beale M., T. Hagan M. and B. Demuth, H., "Neural Network ToolboxTM: User's Guide." MatlabMathWorks, (2013).

\section{BIOGRAPHIES OF AUTHORS}

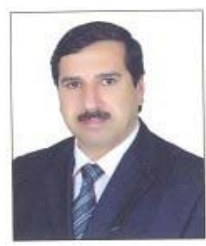

Hussain Attia earned his M.Sc. degree in electronic engineering from the University of Technology, Baghdad, in 1999. He earned his B.Sc. in electronic and communication engineering from the same university in 1991. Currently has Ph.D degree in the power electronics. Hussain's research interests: Power Electronics System, AC \& DC Speed Control Drives, Analog \& Digital Electronic Circuits Design, PWM Inverters (single phase \& three phases). 